\title{
Simulation of temperature distribution by finite element analysis on different components of the EXAFS beamline at INDUS-II synchrotron source
}

\author{
D BHATTACHARYYA ${ }^{1 *}, \mathrm{~S}^{\mathrm{N}} \mathrm{JHA}^{1}, \mathrm{~N} \mathrm{C} \mathrm{DAS}^{1}$, \\ VISHNU VERMA $^{2}$, S G MARKANDEYA ${ }^{2}$ and A K GHOSH ${ }^{2}$ \\ ${ }^{1}$ Spectroscopy Division and ${ }^{2}$ Reactor Safety Division, Bhabha Atomic Research \\ Centre, Mumbai 400 085, India \\ e-mail: dibyendu@magnum.barc.ernet.in
}

MS received 17 March 2005; revised 8 August 2005

\begin{abstract}
An extended X-ray absorption fine structure (EXAFS) beamline is being developed for the INDUS-II synchrotron source. Several optical and mechanical components of the beamline are exposed to high intensity synchrotron radiation while in operation. The temperature rise on different components of the beamline on exposure to the synchrotron beam has been simulated by finite element analysis. Design of the cooling mechanism for each of these components has been carried out and estimation of the temperature rise has also been done incorporating the cooling mechanism.
\end{abstract}

Keywords. Synchrotron; EXAFS; finite element analysis.

\section{Introduction}

An extended X-ray absorption fine structure (EXAFS) beamline for X-ray absorption studies is being developed for set up at the INDUS-II synchrotron source (Das et al 2002, 2003). The INDUS-II source is a $2.5-\mathrm{GeV}$ synchrotron source which is presently being commissioned at the Centre Advanced Technology (CAT), Indore (http://www.cat.gov.in). The INDUS-II synchrotron source is primarily a hard X-ray source and the proposed beamline is designed to carry out extended X-ray absorption (EXAFS) studies in the energy regime of 5 to $20 \mathrm{keV}$. The EXAFS method is a powerful structure determination technique that can be applied to any type of material, e.g. amorphous solids, liquids, solutions, gases, polymers and surfaces (Lytle 1999; Stern 2001; Tournus et al 2002; Ascone et al 2003; Hricovini et al 2003). The proposed EXAFS beamline at INDUS-II is designed to carry out the X-ray absorption measurements in energy dispersive mode, not involving a time-consuming scanning mechanism, and thus can be applied to study in-situ fast and time-resolved processes (Iwasawa 2003).

In the proposed beamline, a single crystal (CC) is bent in the shape of an ellipse and the source $\left(S_{0}\right)$ and sample $\left(S_{3}\right)$ are kept at the two foci of the ellipse (Lee et al 1994) as shown in

\footnotetext{
*For correspondence
} 


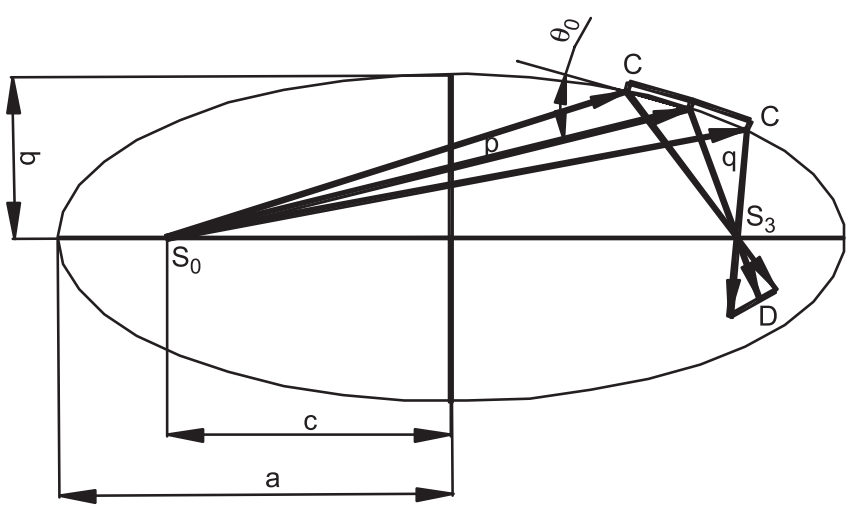

Figure 1. Schematic diagram showing the principle of action of the beamline.

figure 1. White synchrotron radiation from the source $\left(S_{0}\right)$ is made incident on the crystal and gets spatially dispersed in energy. Polychromatic radiation with a particular central energy $\left(E_{o}\right)$ and a certain band-width $(\Delta E)$, depending on the angle of incidence of the beam and its radius of curvature, is then focused on the sample $\left(S_{3}\right)$. Transmitted radiation from the sample is finally detected by a position-sensitive detector (D). Thus the energy-dispersed absorption spectra of the sample, over the entire band-width $(\Delta E)$ around the central energy $\left(E_{o}\right)$, is recorded on the detector simultaneously. The proposed beamline covers the photon energy range of 5 to $20 \mathrm{keV}$ with a bent $\mathrm{Si}(111)$ crystal of $2 d$ value $6.2709 \AA$. The beamline provides band-widths of the order of $0.3,1 \mathrm{keV}$ and $2 \mathrm{keV}$ at photon energies of 5,10 and $20 \mathrm{keV}$ respectively. The average resolution at the detector has been estimated to be $\sim 1 \mathrm{eV}$ per channel (Das et al 1999). The optical and mechanical layouts of the beamline have been described in $\S 2$.

Since INDUS-II is a high-energy photon source, the heat load on the different optical and mechanical components of the beamline under exposure to synchrotron radiation would be considerable. Thus, proper estimation of the rise in temperatures of the different optical and mechanical components of the beamline under the heat load of the synchrotron radiation and optimization of the cooling mechanism for compensating the above heat load are both of the utmost importance. In the present communication, calculation of the temperature profiles of the four major components of the beamline by finite element analysis (FEA), viz. the copper blocks in the beam aperture chamber, the Be window, the tantalum jaws in the slit system and the Si crystal, have been described.

\section{Optical and mechanical layouts of the beamline}

The optical layout of the beamline is shown in figure 2 . The beam coming from the synchrotron source is first collimated by two copper blocks $(\mathrm{K}, \mathrm{K})$ kept at an angle of $15^{\circ}$ with the beam path. The collimated beam, with horizontal divergence of $1.5 \mathrm{mrad}$, then passes through the Be window (B) of suitable thickness, which helps to cutoff the unwanted low-energy part from the continuum. The beam then falls on the Ta slit $\left(S_{1}\right)$ system, which defines the final divergence of the synchrotron beam. The beam emerging from the slit with the required vertical and horizontal divergences now falls on the crystal (CC). After reflection from the crystal, the dispersed beam passes through the second slit $\left(S_{2}\right)$. This slit $\left(S_{2}\right)$ helps in keeping out the scattered radiation, so that the beam gets sharply focused on the sample $\left(S_{3}\right)$. From 

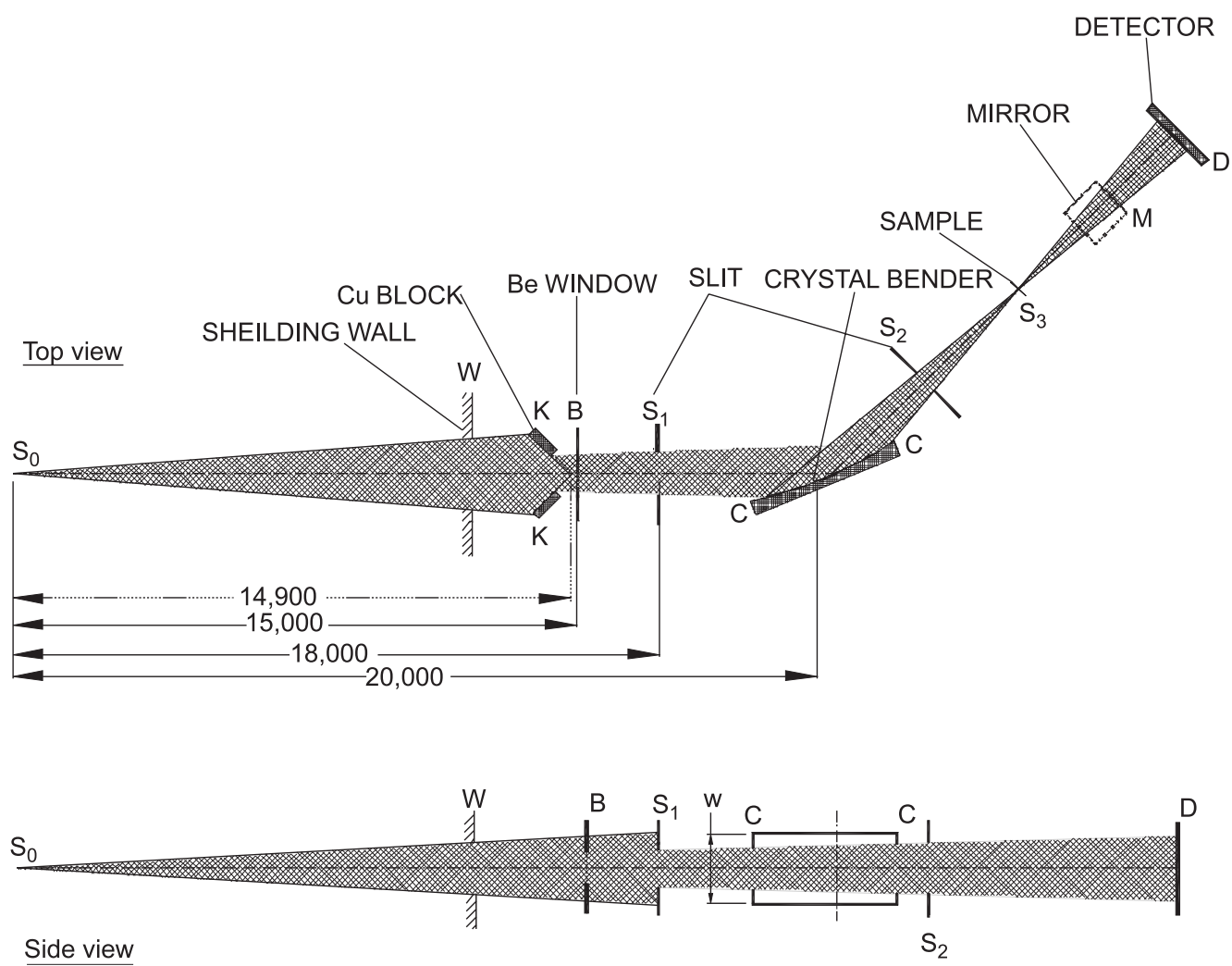

Figure 2. Optical layout of the beamline (dimensions in $\mathrm{mm}$ ).

the sample, the beam diverges further and finally gets detected at the CCD-type positionsensitive detector (D). A plane mirror (M) is used before the detector to cutoff the higher harmonics from the radiation diffracted by the Si crystal. W is the shielding wall that isolates the front-end of the beamline from the rest of the portion.

Some parameters of the beamline, viz. source to Si crystal distance $(p)$, the horizontal beam divergence $\left(U_{m}\right)$ etc. have been decided based on some practical considerations, while other parameters, viz. the band-widths at different energies $(\Delta E)$, mean radius of curvature of the crystal $\left(R_{0}\right)$, crystal to sample distance $(q)$ etc. have been calculated using standard optical relations (Das et al 1999). These parameters have been listed in table 1 for two extreme energies of 5 and $20 \mathrm{keV}$ and one intermediate energy of $10 \mathrm{keV}$.

The corresponding mechanical layout of the post-shielding wall portion of the beamline has been shown in figure 3, where the beam aperture chamber (which contains the copper blocks), the Be window, the slit system and the crystal bender are clearly shown. The two beam-view chambers shown in the above figure are used for periodical monitoring of the beam path by stopping the beam on a scintillation screen and viewing the position of the visible spot generated through a digital camera mounted on the view port of the chamber. The experimental station as shown in the above figure basically consists of a large goniometer, with the crystal bender chamber mounted on its $\theta$ axis, while the sample and detector stages are mounted on the $2 \theta \mathrm{arm}$. The most critical mechanical component of the beamline is the crystal bender, 
Table 1. EXAFS beamline variable parameters.

\begin{tabular}{lccc}
\hline Parameter & \multicolumn{3}{c}{ Value $(\mathrm{s})$} \\
\hline Crystal type & \multicolumn{3}{c}{ Si $(111)$} \\
$2 d$ value $(\AA)$ & 6.2709 \\
Source to crystal distance $(p)(\mathrm{mm})$ & \multicolumn{3}{c}{20,000} \\
Horizontal beam divergence $\left(U_{m}\right)(\mathrm{mrad})$ & \multicolumn{3}{c}{1.5} \\
Photon energy $\left(E_{o}\right)(\mathrm{eV})$ & 5000 & 10,000 & 20,000 \\
Band pass $(\Delta E)(\mathrm{eV})$ & 297 & 1123 & 2000 \\
Bragg angle $\left(\theta_{0}\right)(\mathrm{deg})$. & 23.28 & 11.40 & 5.67 \\
Vertical divergence $\left(V_{m}\right)(\mathrm{mrad})$ & 0.69 & 0.53 & 0.40 \\
Crystal length $(l)(\mathrm{mm})$ & 75.9 & 151.8 & 303.5 \\
Crystal radius $\left(R_{0}\right)(\mathrm{mm})$ & 2803 & 6287 & 26,550 \\
Crystal to sample distance $(q)(\mathrm{mm})$ & 570 & 641 & 1404 \\
\hline
\end{tabular}

the design of which has been described thoroughly in our earlier communication (Das et al 2004).

Figure 4 shows the schematic of the beam aperture system showing the copper blocks mounted on two flanges at an angle of $30^{\circ}$ with each other. Figure 5 shows the schematic diagram of the Be window with the relevant dimensions, which is mounted on a copper block, which in turn is mounted on an SS flange. Figure 6 shows the schematic of a tantalum jaw of the slit system with all dimensions, while figure 7 shows the schematic diagram of the crystal mounted on the crystal bender. In the following, the results of the heat load calculations on the above four major components, viz. the $\mathrm{Cu}$ blocks in the beam aperture system, the Be window, the Ta jaws in the slit system and the Si crystal have been described.

\section{Heat load calculations}

For estimation of the heat load on the different components under synchrotron radiation, the dimensions of the illuminated and un-illuminated portions of all the components have first been estimated using the horizontal and vertical divergences of the beam (as given in table 1) and the distances between the different components as given in figure 2 . These dimensions have been shown in table 2. The power spectrum falling on each of the components have been calculated from the given parameters of the INDUS-II source and are shown in figure 8 . As can be seen from table 1, the vertical divergence of the synchrotron beam is different for different photon energies of interest and the vertical opening of the Ta slit is changed to control the vertical divergence. Accordingly, the dimensions of the illuminated portions of the jaws of the slit system are different for different energies. These dimensions have been calculated for three representative energies viz., 5, 10 and $20 \mathrm{keV}$ and have been shown in table 2, while the corresponding power spectra have been shown in figure 8. Similarly, the dimensions of the illuminated portion and the power spectrum falling on the Si crystal would vary with change in photon energy and the corresponding values for the above three photon energies $(5,10$ and $20 \mathrm{keV})$ are given in table 2 and figure 8 .

Moreover, the characteristic of the synchrotron beam is such that the photons of all energies are not uniformly distributed along the vertical plane, rather the higher energy photons are 


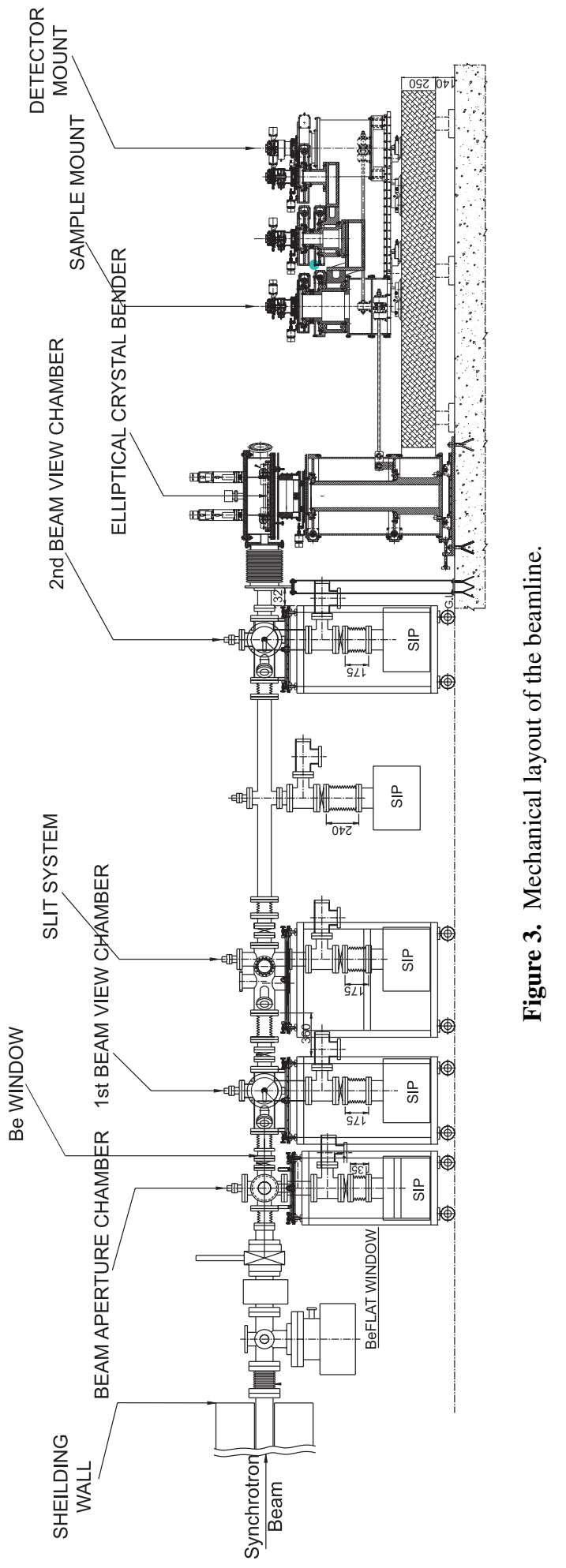




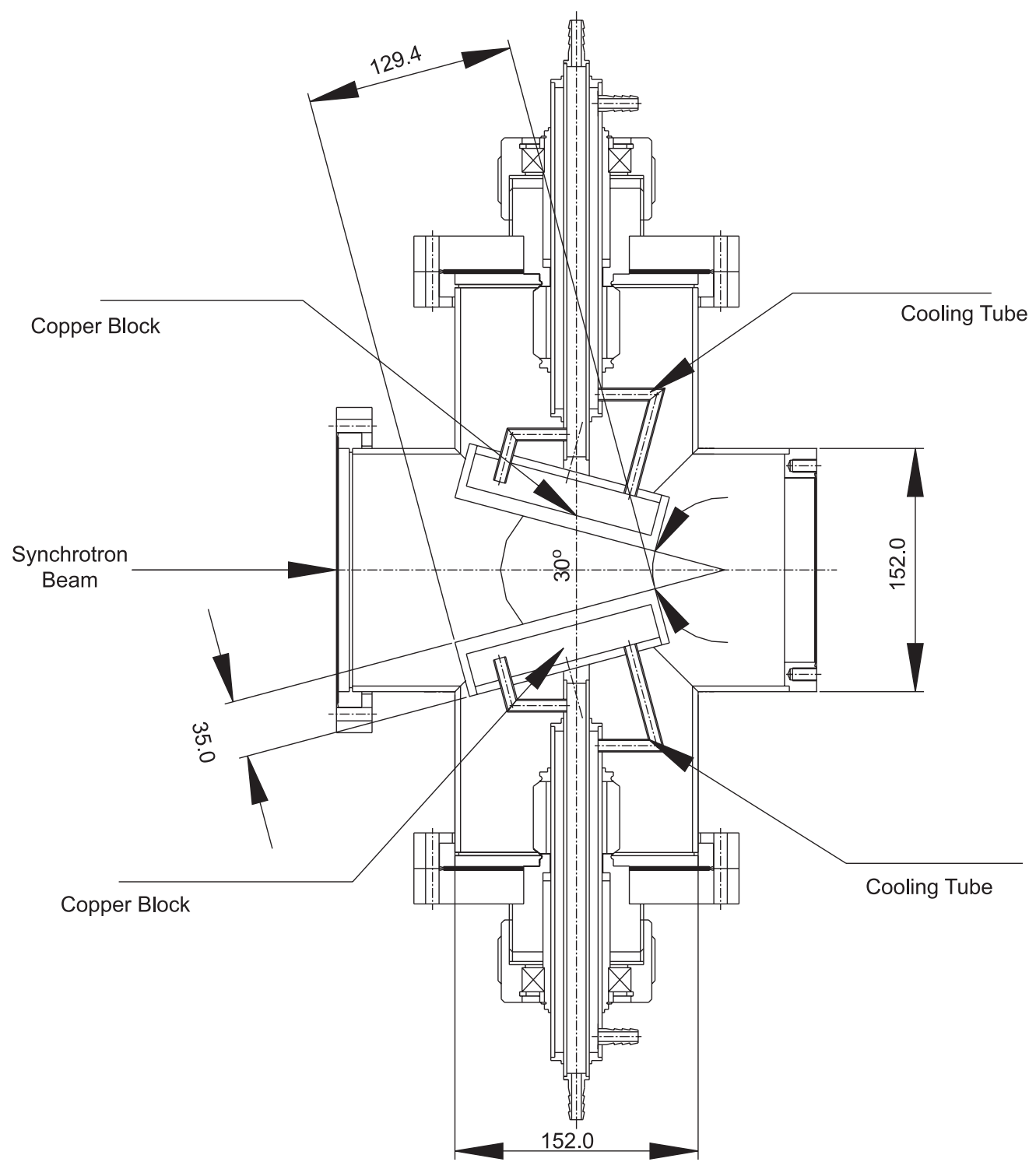

Figure 4. Schematic diagram of the beam aperture chamber (top view) showing the copper blocks (dimensions in $\mathrm{mm}$ ).

confined near about the axis of the beam. The maximum vertical emission angle ( $V_{m}$ in mrad) for a particular photon of wavelength $\lambda$ (in $\AA$ ) is given by (Koch et al 1983):

$$
\begin{aligned}
V_{m} & =(3.08 / \gamma)\left(\lambda / \lambda_{c}\right)^{0.38}, \\
\gamma & =1957.0 E_{S}, \quad \lambda_{c}=18.6 /\left(B_{S} E_{S}\right)
\end{aligned}
$$

where, $E_{S}$ is the operating energy of the synchrotron source in $\mathrm{GeV}$ ( $2.5 \mathrm{GeV}$ for INDUS-II) and $B_{S}$ is the magnetic field of the storage ring in tesla (1.502 tesla for INDUS-II).

Using the above relation, the maximum vertical distance up to which photons of a particular 

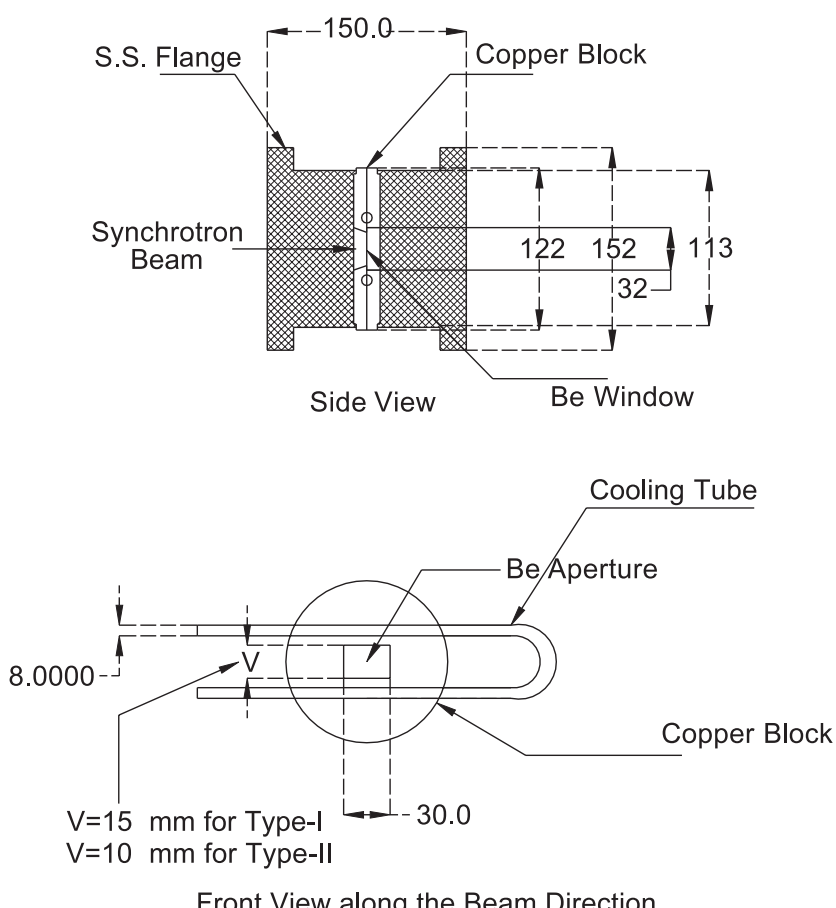

Front View along the Beam Direction

Figure 5. Schematic diagram of the Be window mounted on the copper blocks (dimensions in $\mathrm{mm})$.

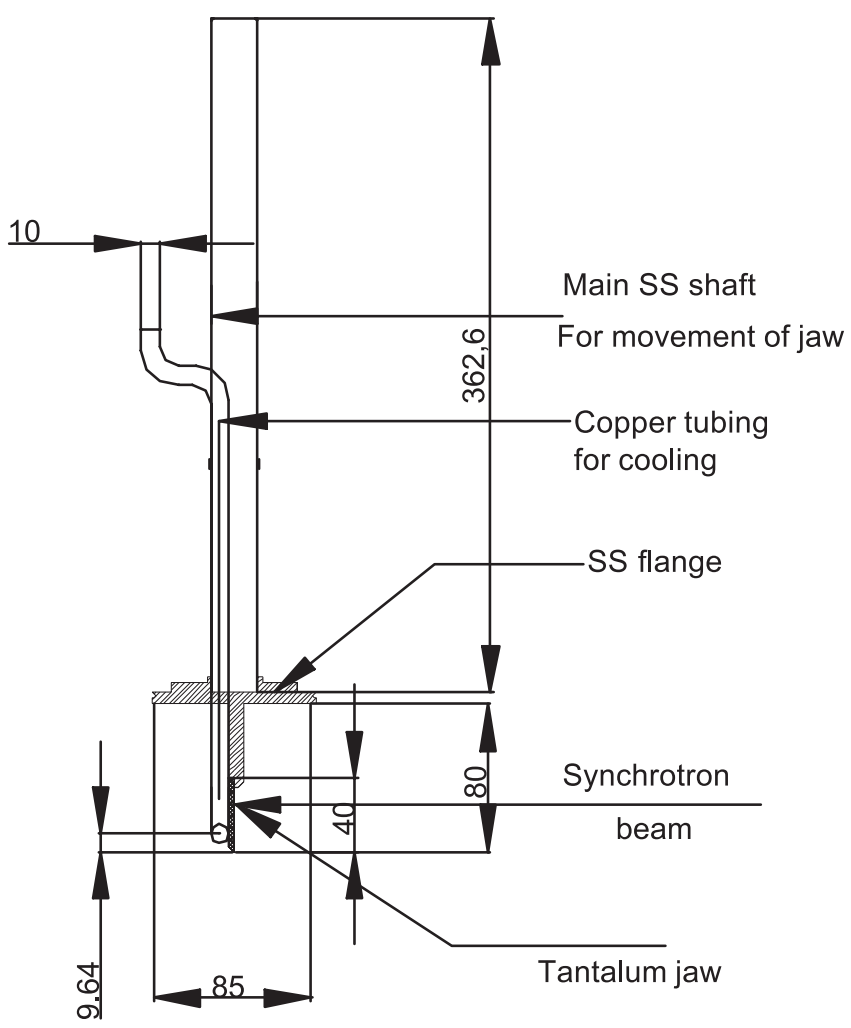

Figure 6. Schematic diagram of a Ta jaw of the slit system (dimensions in $\mathrm{mm}$ ). 


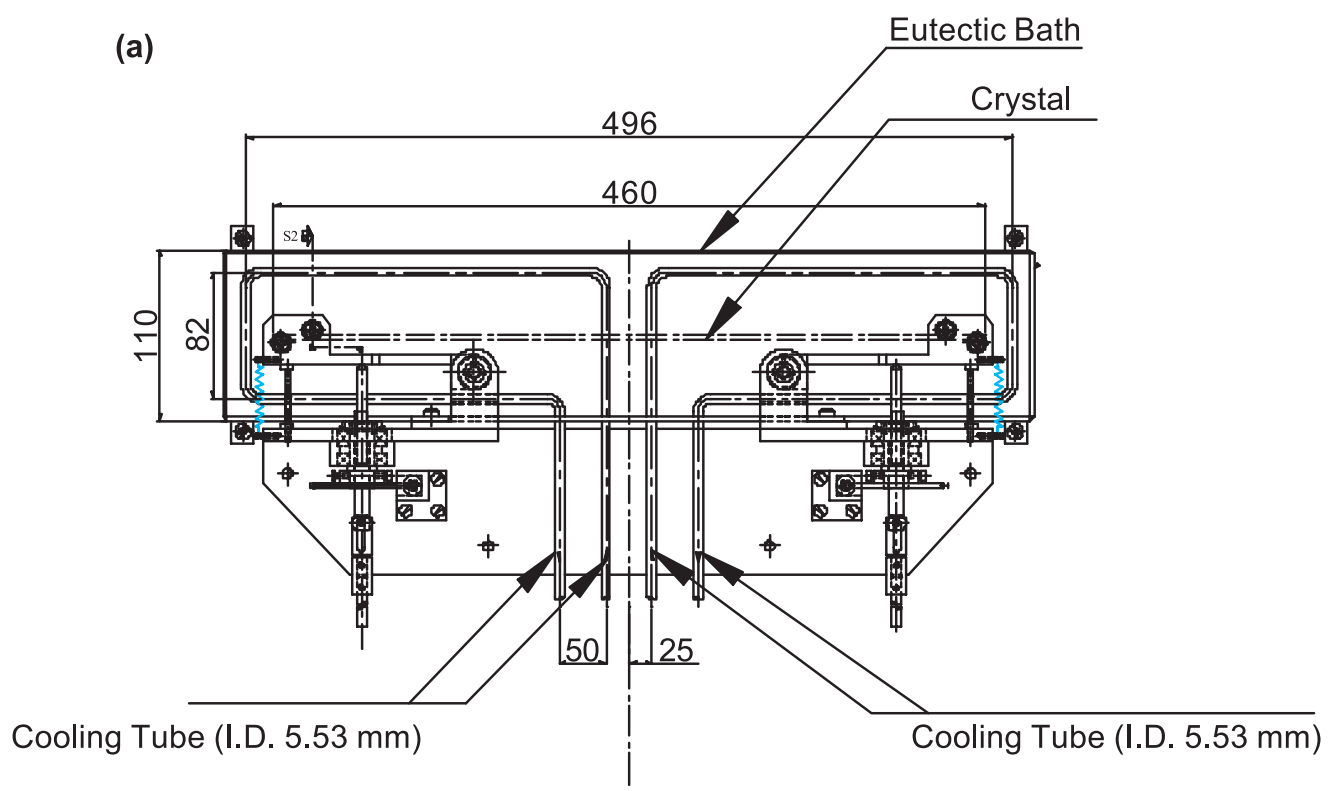

(b)

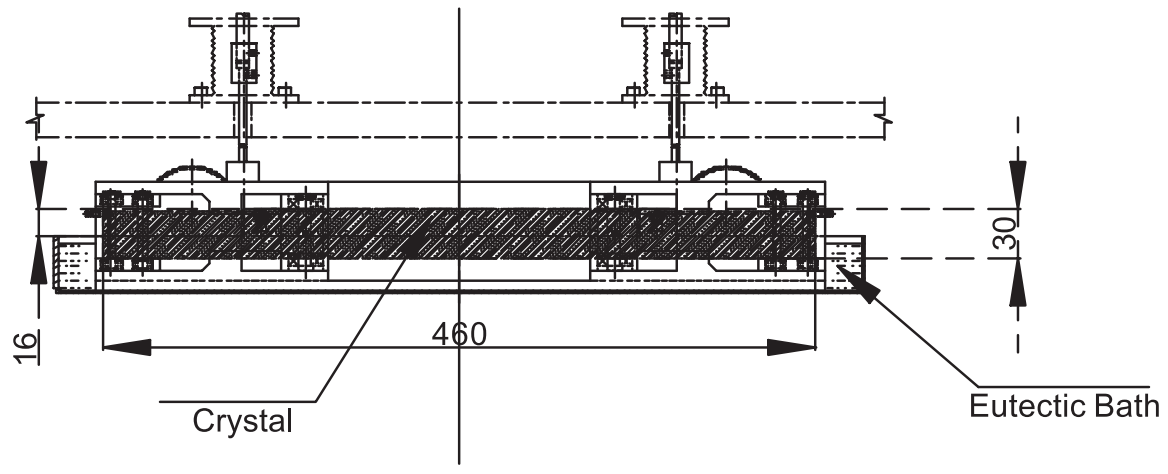

Figure 7. Schematic diagram of the Si crystal with the crystal bender in the Ga-In eutectic bath (dimensions in $\mathrm{mm}$ ) (a) top view (b) front view.

Table 2. Dimensions of the illuminated and un-illuminated portions of the different components.

\begin{tabular}{|c|c|c|c|c|c|c|c|c|c|}
\hline \multirow{3}{*}{$\begin{array}{l}\text { Optical } \\
\text { component }\end{array}$} & & & \multicolumn{7}{|c|}{ Dimension of illuminated area } \\
\hline & \multicolumn{2}{|c|}{ Overall dimension } & \multicolumn{3}{|c|}{$h^{*}(\mathrm{~mm})$} & \multicolumn{3}{|c|}{$v^{* *}(\mathrm{~mm})$} & \multirow{2}{*}{$\begin{array}{c}\text { Thickness } \\
(\mathrm{mm})\end{array}$} \\
\hline & $H^{*}(\mathrm{~mm})$ & $V^{* *}(\mathrm{~mm})$ & $5 \mathrm{kV}$ & $10 \mathrm{kV}$ & $20 \mathrm{kV}$ & $5 \mathrm{kV}$ & $10 \mathrm{kV}$ & $20 \mathrm{kV}$ & \\
\hline $\mathrm{Cu}$ block & 128 & 35 & \multicolumn{6}{|c|}{ Fully illuminated } & 20 \\
\hline Be window & 30 & $\begin{array}{c}15 \text {-type-I } \\
10 \text {-type-II }\end{array}$ & 22.5 & 22.5 & 22.5 & \multicolumn{3}{|c|}{ Fully illuminated } & 0.1 \\
\hline Ta slit & 70 & 40 & 27.0 & 27.0 & 27.0 & 11.79 & 13.23 & 14.40 & 3.0 \\
\hline Si crystal & 460 & 30 & 75.9 & 151.8 & 303.5 & 13.7 & 10.5 & 8.1 & 3.0 \\
\hline
\end{tabular}

${ }^{*}$ Horizontal dimension; ${ }^{* *}$ vertical dimension 


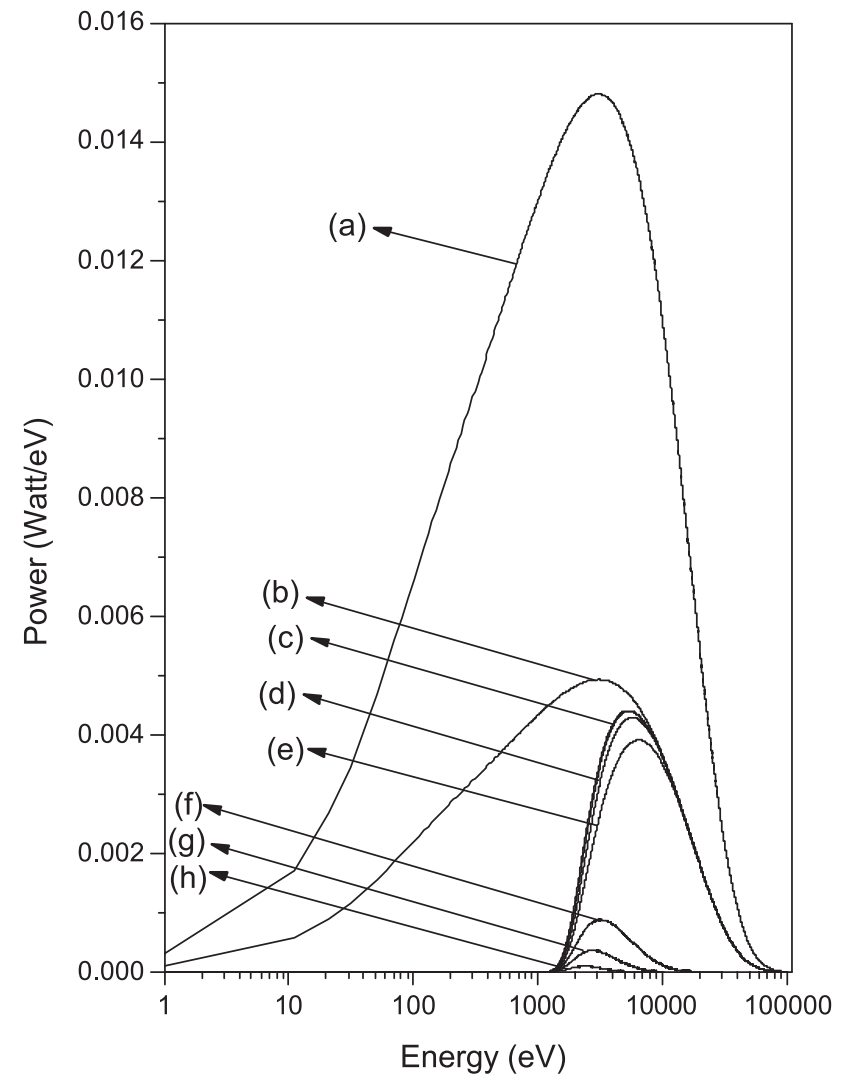

Figure 8. Power spectrum falling on different components of the beamline: (a) Cu block, (b) Be window, (c) $\mathrm{Si}$ crystal at $5 \mathrm{keV}$, (d) $\mathrm{Si}$ crystal at $10 \mathrm{keV}$, (e) $\mathrm{Si}$ crystal at $20 \mathrm{keV}$, (f) Ta jaw at $20 \mathrm{keV}$, (g) Ta jaw at $10 \mathrm{keV}$, and (h) $\mathrm{Ta}$ jaw at $5 \mathrm{keV}$.

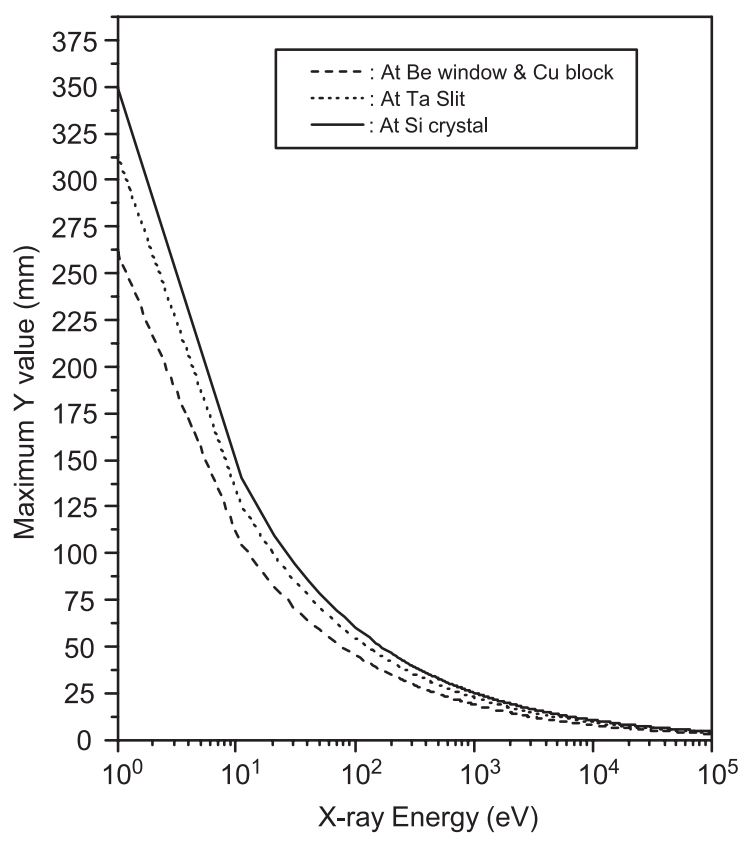

Figure 9. Vertical distribution of photon energy in the synchrotron beam at different elements. 


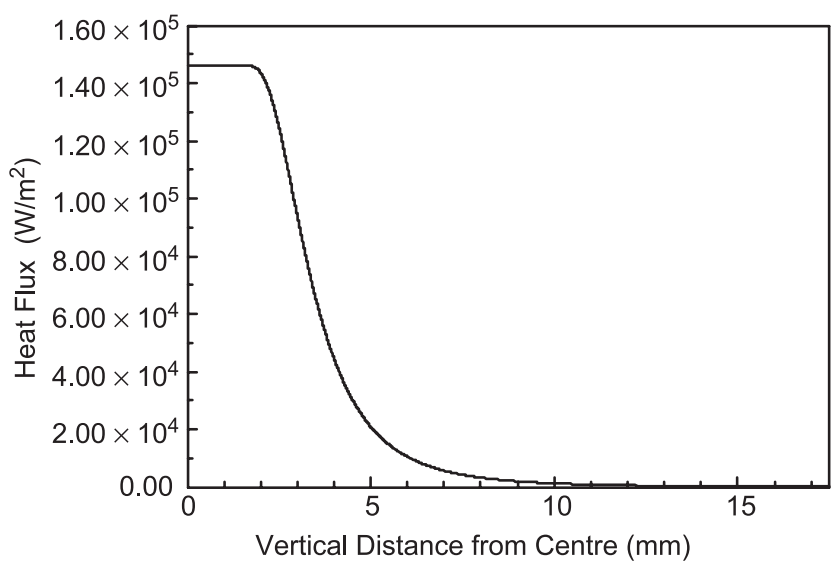

Figure 10. Variation of heat flux with vertical distance at the $\mathrm{Cu}$ block.

energy are available is calculated at the four components, viz. the $\mathrm{Cu}$ block, the Be window, Ta jaw of the slit system and Si crystal, and these are shown in figure 9. Then using the plots given in figures 8 and 9 , the actual distribution of heat flux falling on the different components are calculated, which is the fundamental input for the temperature profile calculations. Figure 10 shows the distribution of the heat flux for a representative component, viz. the $\mathrm{Cu}$ block. From the incident heat flux values, the total power absorbed in each of the four components being discussed here, have been estimated using their X-ray absorption coefficients values available in the literature (Henke et al 1993). The values of total incident, transmitted and absorbed power at each of these components under the heat flux of the synchrotron radiation have been shown in table 3. The incident power on a component has been considered to be equal to the transmitted power from its predecessor component. Using the absorbed heat flux values, the temperature distributions on the different components under exposure to synchrotron radiation have been obtained using finite element analysis. Thermal properties of the different materials have been taken from the CRC Handbook (Lide 1999) and the basic assumptions in the calculations are:

(i) Steady state heat transfer;

(ii) Heat loss $\left(Q_{S}\right)$ from the surface is only due to radiation and is given by:

$$
Q_{S}=\sigma \varepsilon A\left(T_{S}^{4}-T_{A}^{4}\right)
$$

where $\sigma$ is Boltzman's constant, $\varepsilon$ is the emissivity, $A$ is the area of the surface and $T_{S}$ and $T_{A}$ are the temperatures of the surface and the ambient respectively;

(iii) energy absorbed within one component is assumed to be the heat flux at the surface;

(iv) emissivity is 0.3 , the same for all the components, and is independent of temperature.

With the above assumptions, the 3-dimensional steady-state heat transport equation in Cartesian co-ordinates can be given as:

$$
\frac{\partial}{\partial x}\left(k \frac{\partial T}{\partial x}\right)+\frac{\partial}{\partial y}\left(k \frac{\partial T}{\partial y}\right)+\frac{\partial}{\partial z}\left(k \frac{\partial T}{\partial Z}\right)=0,
$$

which is solved numerically by finite element analysis (FEA) using NISA (Numerically Integrated System for Analysis, M/s. EMRC, USA) software, where $k$ is the thermal conductivity. 
Table 3. Energy balance on the four components under discussion.

\begin{tabular}{|c|c|c|c|c|}
\hline $\begin{array}{l}\text { Name of } \\
\text { the component }\end{array}$ & & $\begin{array}{c}\text { Power } \\
\text { incident (W) }\end{array}$ & $\begin{array}{c}\text { Power } \\
\text { transmitted (W) }\end{array}$ & $\begin{array}{c}\text { Power } \\
\text { absorbed (W) }\end{array}$ \\
\hline $\mathrm{Cu}$ block & & 373.45 & 93.45 & 280.0 \\
\hline Be window & & 93.45 & 80.96 & 12.49 \\
\hline \multirow[t]{3}{*}{ Ta slit } & $\begin{array}{c}\text { Vertical } \\
\text { divergence } \\
(0.40 \mathrm{mrad})\end{array}$ & 80.96 & 76.58 & 4.38 \\
\hline & $\begin{array}{c}\text { Vertical } \\
\text { divergence } \\
(0.53 \mathrm{mrad})\end{array}$ & 80.96 & 79.79 & 1.17 \\
\hline & $\begin{array}{c}\text { Vertical } \\
\text { divergence } \\
\text { (0.68 mrad) }\end{array}$ & 80.96 & 80.75 & 0.21 \\
\hline \multirow[t]{3}{*}{ Si crystal } & $\begin{array}{c}\text { Vertical } \\
\text { divergence } \\
(0.40 \mathrm{mrad})\end{array}$ & 76.58 & 10.0 & 66.58 \\
\hline & $\begin{array}{c}\text { Vertical } \\
\text { divergence } \\
(0.53 \mathrm{mrad})\end{array}$ & 79.79 & 10.01 & 69.77 \\
\hline & $\begin{array}{c}\text { Vertical } \\
\text { divergence } \\
(0.68 \mathrm{mrad})\end{array}$ & 80.75 & 10.01 & 70.74 \\
\hline
\end{tabular}

Figure 11 shows the 3-D view of the temperature distribution on 1/4th segment of the copper block, while figures 12,13 and 14 show the temperature distribution on the half of the surface facing the synchrotron radiation at the Be window, Ta slit and Si crystal respectively, under exposure to the synchrotron radiation. It is found that there is significant temperature rise in the range of $450-600^{\circ} \mathrm{C}$ at the different components of the beamline under exposure to synchrotron radiation.

After the heat transfer calculations for the different components of the beamline, efforts have been made to design the proper cooling channels for efficient cooling of the components. Different cooling arrangements have been considered for different components.

Convective cooling by water has been considered for the copper blocks. Cooling tubes with circular cross-sections having a diameter of $5 \mathrm{~mm}$ have been considered as shown in figure 4 . The heat transfer problem in the copper blocks has been solved under the conjugate heat transfer model. In this model, fluid flow is also modelled by solving the Navier-Stokes equation with energy and continuity. Under this model, the energy transfer from fluid to solid or vice versa is modelled so that there is no need to define the heat transfer coefficient as a boundary condition. Considering the symmetry in the copper block design and for the sake of saving computational time, half the copper block is modelled. A parametric study has been done by varying flow velocity and temperature of water at the inlet and the results are shown in table 4 . It has been found that beyond a certain value, the effect of flow velocity on improvement of heat transfer coefficient is insignificant. It shows that initially, with increase in flow velocity, the maximum temperature reduces rapidly but, subsequently, the reduction 


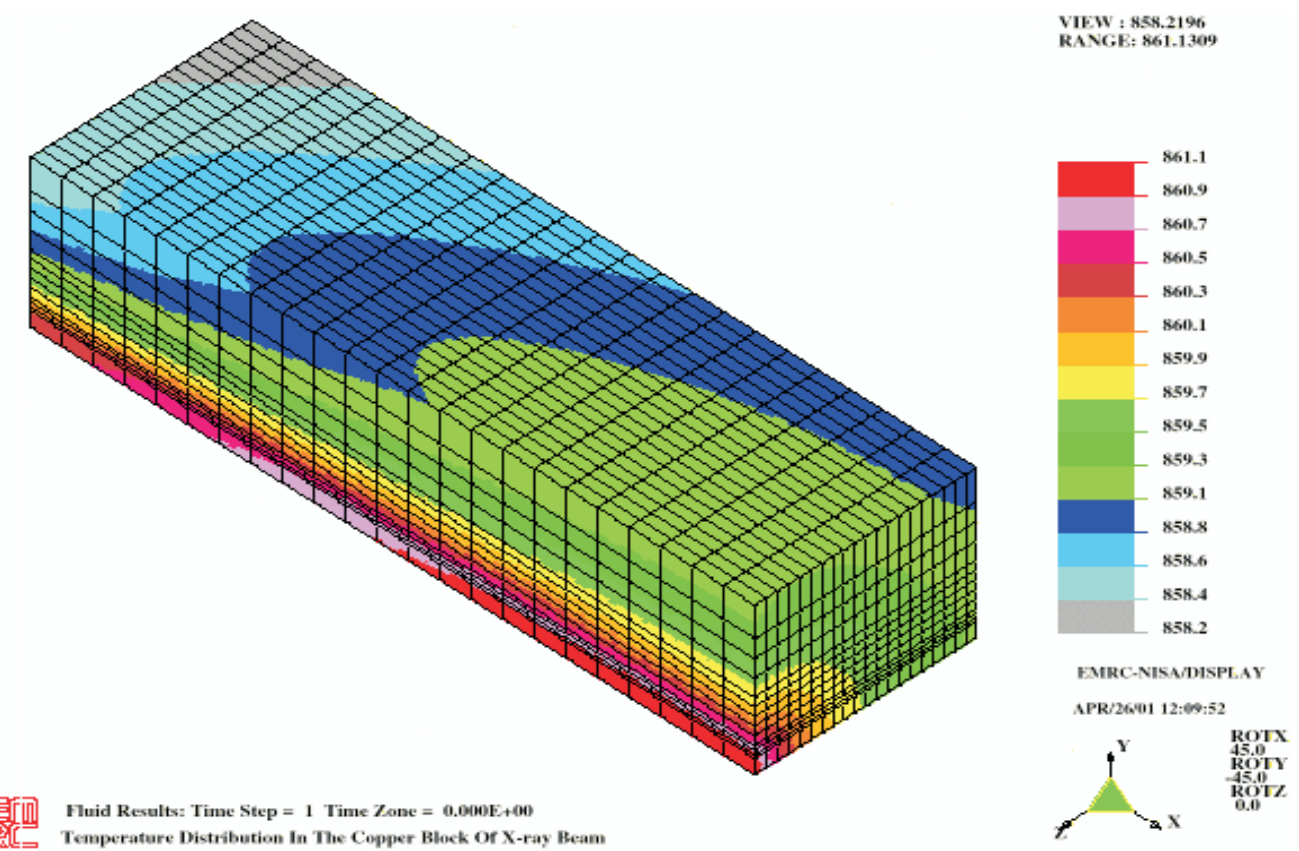

Figure 11. Temperature profile on the Cu-block under the heat load of synchrotron radiation (3-D view) (temperatures in kelvin).
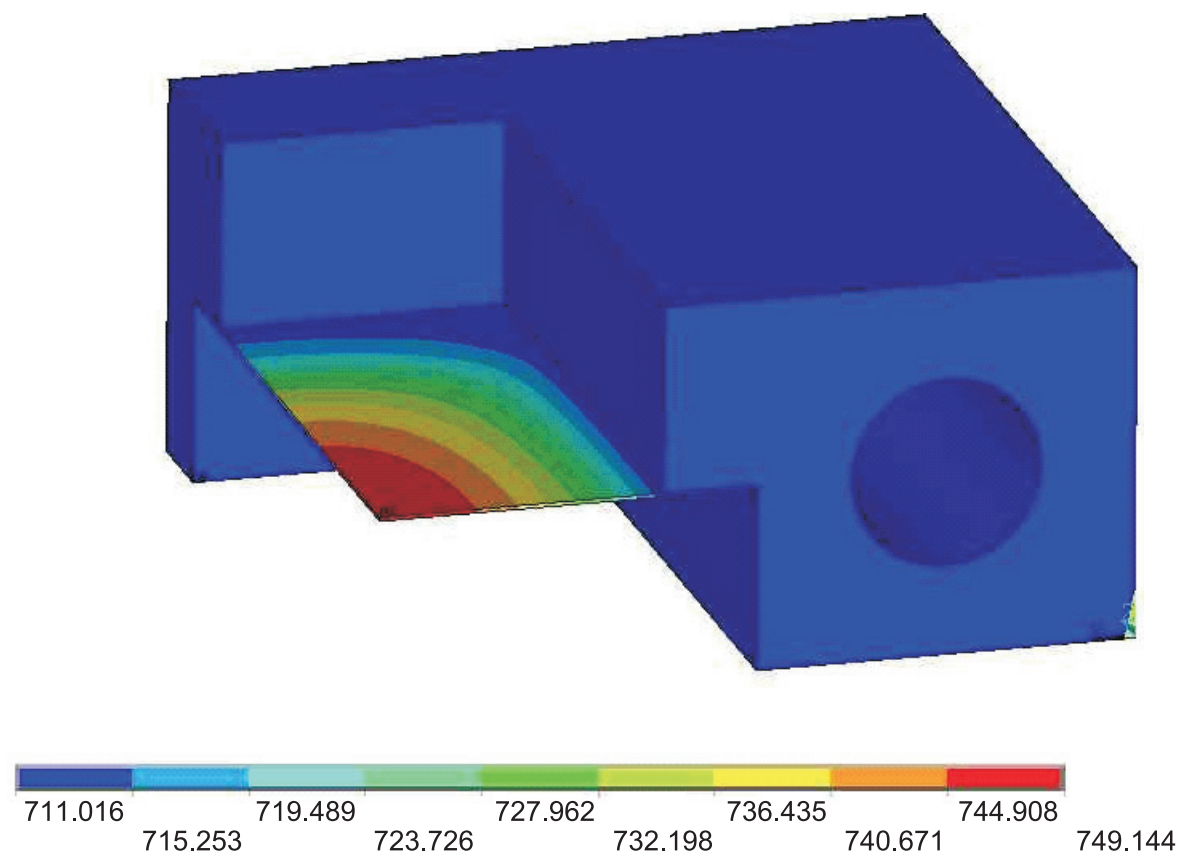

Figure 12. Temperature profile on one-half of the surface of the Be window facing the synchrotron beam (temperatures in kelvin). 

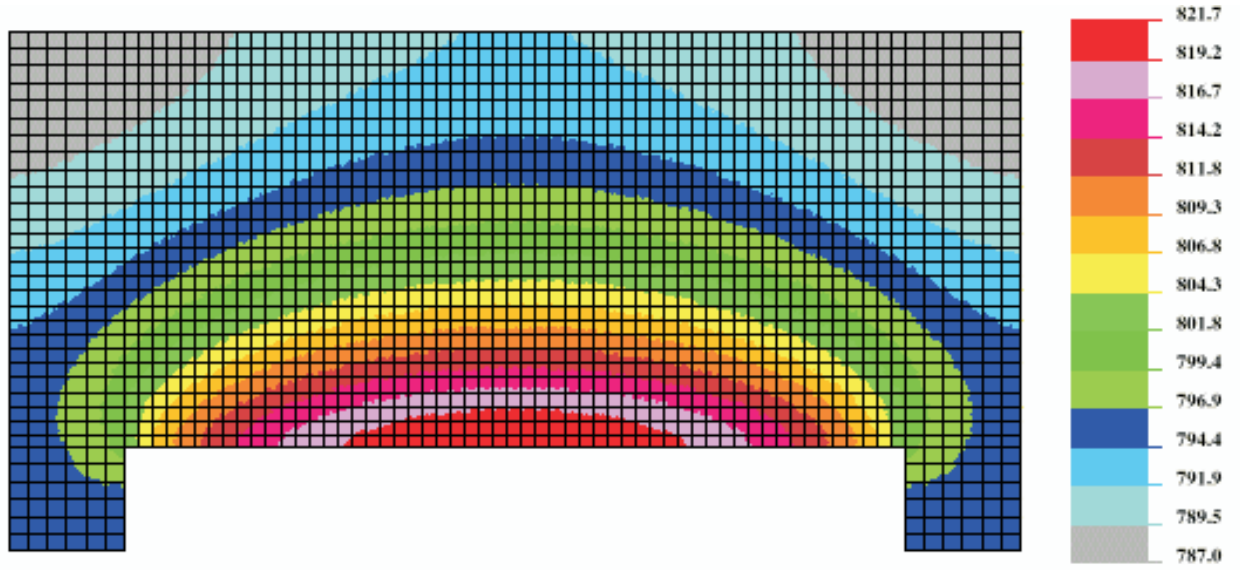

EMRC-NISATSHLAY

MAY/25:01 15:20:46

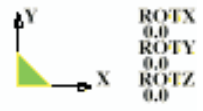

写四 Fluid Results: Time Step = 1 Time Zone = 0.000E+ +00

Temperature Distrihution In The Ta-sL.TT of X-ray Beam Source

Figure 13. Temperature profile on one-half of the surface of the Ta slit facing the synchrotron radiation (temperatures in kelvin).

YIEW: 5305932
R.NGE: 758,0946

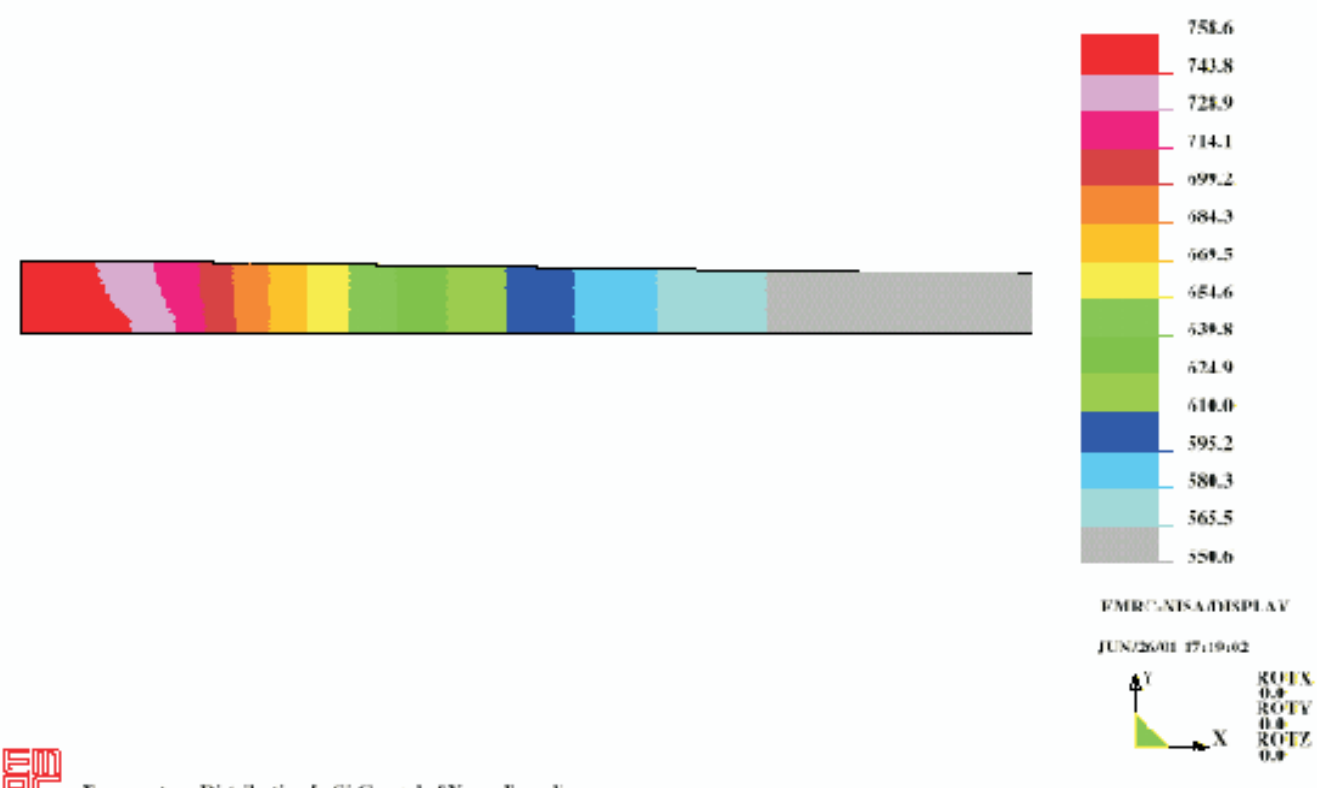

Teaprature Distributian Le Si-Ciysal of X-ray Feantim

Figure 14. Temperature profile on one-half of the surface of the Si crystal facing the synchrotron radiation (temperatures in kelvin). 
Table 4. Maximum and minimum temperature of copper block (with convective cooling): Effect of flow velocity of water.

\begin{tabular}{lccc}
\hline $\begin{array}{l}\text { Water inlet } \\
\text { temperature }\left({ }^{\circ} \mathrm{C}\right)\end{array}$ & $\begin{array}{l}\text { Velocity } \\
\left(\mathrm{m} \mathrm{s}^{-1}\right)\end{array}$ & $T_{\max }(\mathrm{K})$ & $T_{\min }(\mathrm{K})$ \\
\hline & 0 & 819.7 & 816.7 \\
25 & 0.1 & 337.3 & 298 \\
25 & 0.5 & 326.7 & 298 \\
15 & 0.5 & 316.8 & 288 \\
25 & 0.6 & 326.2 & 298 \\
\hline
\end{tabular}

is insignificant. Due to reduction in inlet temperature, the maximum temperature also reduces though not in the same proportion due to radiation heat transfer. Temperature contour plot is shown in figure 15 for a velocity of $500 \mathrm{~mm} \mathrm{~s}^{-1}$ which has been found to be sufficient for maintaining the temperature of the copper blocks within reasonable limits. Results are also obtained to study the effect of shifting the cooling tubes towards the heat flux surface by $7 \mathrm{~mm}$ to reduce the temperature due to reduction in thermal resistance. However, it has been found that due to the high thermal conductivity of copper, the maximum temperature drops only by $0.5^{\circ} \mathrm{C}$ in the process.

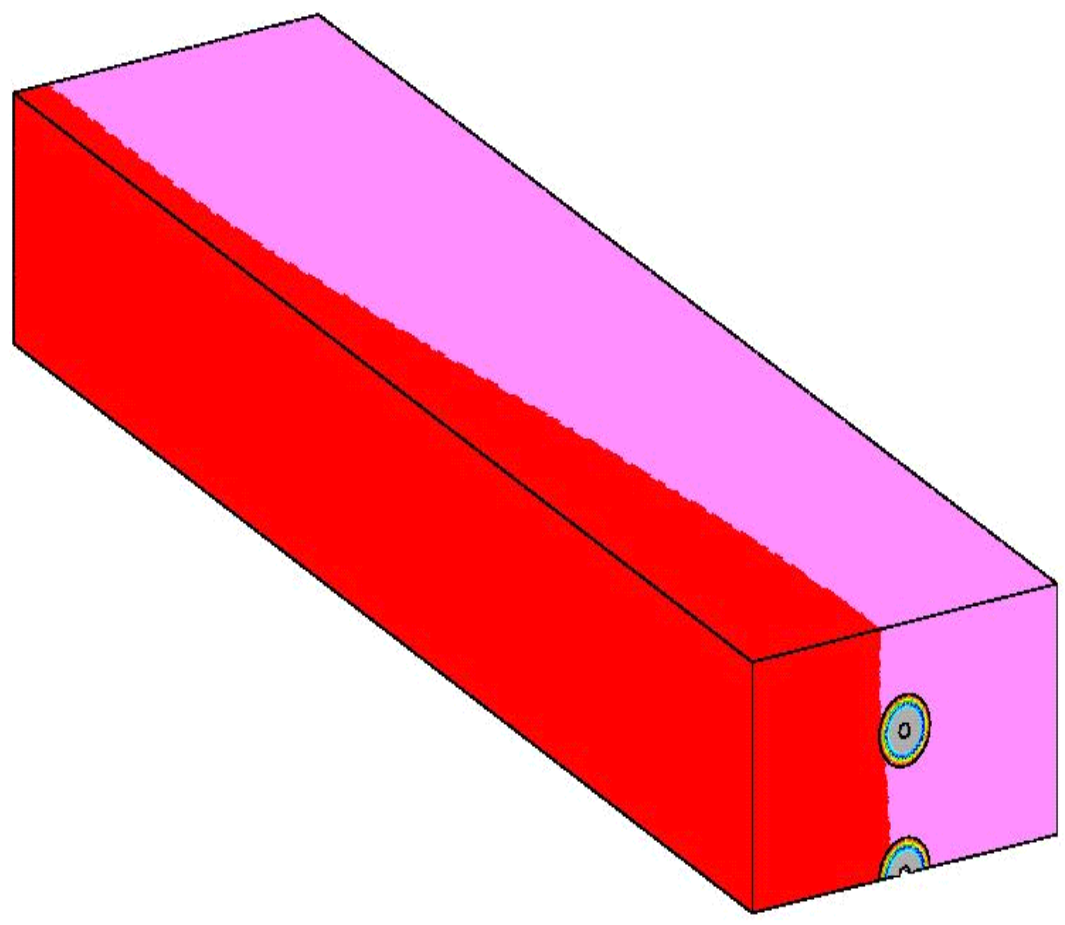

VIEW : 287.7661 RANGE: 316.8147

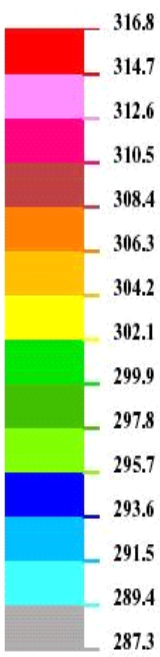

EMRC-NISA/DISPLAY APR/02/02 15:37:38

PY ROTX

Figure 15. Temperature profile of the copper block with $15^{\circ} \mathrm{C}$ water flowing at a rate of $500 \mathrm{~mm} \mathrm{~s}^{-1}$ through the cooling channels as shown in the figure (temperatures in kelvin). 
For cooling of the beryllium window, a bent copper tube is inserted and brazed into the two holes through the copper blocks holding the Be window as shown in figure 5. The size of the Be window to be used in the beamline and the mounting flanges are also shown in figure 5 . A parametric study has been conducted by varying the heat transfer coefficient due to change in flow rate of the fluid. The temperature distribution of the Be window is obtained using the conduction model.

In the present work, calculations for temperature distribution under the heat load of synchrotron radiation have been carried out using the conjugate heat transfer model in case of the copper blocks. As has been discussed earlier, in the conjugate heat transfer approach there is no need to define heat transfer coefficient and heat transfer between solid and fluid is taken care of in the program by solving the Navier-Stokes equation in the fluid region. This approach involves complicated geometrical modelling and large amounts of computational time. Thus, in case of elements where complicated geometry is involved, viz. Be window, Slit systems etc., temperature distribution was evaluated by direct approach with the conduction model, using a heat transfer coefficient. It is generally seen that temperature distribution results obtained using the direct approach do not differ much from that obtained using the conjugate heat transfer model.

In the conduction model, only the 3-D steady-state heat conduction equation has to be solved in which the convection heat transfer coefficient and radiation heat transfer coefficient are supplied as boundary conditions. Since the Be windows are used under ultra high vacuum conditions, radiation heat transfer from the outer surface of the window and convective heat transfer to the fluid (water) has been considered. Thus, in this case the boundary conditions used for solving the heat transport equations are the radiation boundary conditions, given by (2) and the convective boundary condition for the tube surface, given as

$$
-k \frac{\mathrm{d} T}{\mathrm{~d} n}=h\left(T_{S}-T_{\text {fluid }}\right),
$$

where, $n$ is the normal to the surface and $h$ is the convective heat transfer coefficient which depends upon the flow rate of the fluid (water) and is related to the dimensionless Nusselt number $(\mathrm{Nu})$ by the following equation (Eckert 1950):

$$
h d / k=\mathrm{Nu},
$$

$d$ and $L$ are respectively the diameter and length of the cooling tube.

In case of forced convection, the Nusselt number in turn is related to the Reynolds number (Re) and Prandtl number (Pr) by the following relation (Eckert 1950):

$$
\mathrm{Nu}=0.116\left[(\mathrm{Re})^{2 / 3}-125\right](\operatorname{Pr})^{1 / 3}\left[1+(d / L)^{2 / 3}\right]\left(\mu_{B} / \mu_{W}\right)^{0.14},
$$

where, $\mu_{B}$ and $\mu_{W}$ are the dynamic viscosity of the liquid at the bulk temperature and at the wall temperature respectively.

Reynolds number $(\mathrm{Re})$ is given by:

$$
\operatorname{Re}=\rho u_{\infty} L / \mu_{B},
$$

where $\rho$ is the density and $u_{\infty}$ is the velocity of the liquid far from the contact surface.

On the other hand, Prandtl number $(\mathrm{Pr})$ is given by:

$$
\operatorname{Pr}=v / \alpha,
$$

where $\alpha$ is the thermal diffusivity and $v$ is the kinematic viscosity of the liquid. 
Equation (7) is valid for the transition zone with Reynolds number varying from 2500 to 6000 and for turbulent flow, the Nusselt number $(\mathrm{Nu})$, can be given as:

$$
\mathrm{Nu}=0.0243 \operatorname{Re}^{0.8} \operatorname{Pr}^{0.4} .
$$

With the above boundary conditions, the heat flow equations have been solved by the finite element method and the temperature distributions of the Be window have been obtained. Two types of windows have been analysed as shown in figure 5. In case of type-I beryllium window, the vertical dimension of Be foil facing the incident X-ray is $15 \mathrm{~mm}$, while for type-II beryllium window, the vertical dimension facing the incident $X$-ray is $10 \mathrm{~mm}$, the horizontal dimensions in both the cases being $30 \mathrm{~mm}$. Figures 16a and b show the temperature distributions on the two types of Be windows for heat transfer coefficients of $h=2500 \mathrm{Wm}^{-2} \mathrm{~K}^{-1}$ respectively. It has been observed that with the cooling arrangement, the temperature of the central portion of the Be window could be brought down to below $60^{\circ} \mathrm{C}$ in case of type-II beryllium window. A parametric study by varying the heat transfer coefficient has also been carried out and it has been found that the reduction in temperature by increasing the heat transfer coefficient from 2500 to 5000 is only $2^{\circ} \mathrm{C}$.

The cooling of the slit assembly is done by brazing a copper tube to the back of the tantalum jaw as shown in figure 6 . The dimensions of the jaws as well as the cooling tubes are also shown in figure 6 . The heat is dissipated through forced cooling by passing water through the copper coils and by radiation loss to the ambient. The temperature of the ambient and water is assumed to be $300 \mathrm{~K}$, and the temperature distribution on the tantalum jaws due the heat load of synchrotron radiation has been obtained by using the boundary conditions as discussed above. Parametric studies have been carried out with different flow rates of water. The temperature distribution on a tantalum jaw for $2.0 \mathrm{~m} \mathrm{~s}^{-1}$ flow rate of water is shown in figure 17. Temperatures of the major portions of the Ta jaws are found to be below $60^{\circ} \mathrm{C}$ with the above cooling arrangement.

The cooling of the bendable Si crystals is also a challenging task. Strains are generated in the crystal under bent condition due to the high heat load which in turn generates distortion of the Bragg planes and bending radius of the crystal leading to the degradation of its focusing and dispersive properties. Thus, to get perfect focusing and dispersion using bent crystal optics efficient cooling is required, which is also a challenging task for dynamically bent crystals. As has been discussed earlier, the crystal in this case is mounted on a bender and would be bent at different radii of curvature depending on the energy range of interest, and so major heat dissipation has to take place through a liquid medium. In this case $\mathrm{Ga}-\mathrm{In}$ eutectic liquid (with $89 \% \mathrm{Ga}$ and $21 \% \mathrm{In}$ ) is used which has a melting point of $15.3^{\circ} \mathrm{C}$. A portion of the crystal is dipped in a static Ga-In liquid bath and heat is dissipated by passing cold water through copper tube inside the bath. The ambient temperature of the bath is maintained at room temperature. The heat transfer is considered to take place here through natural convection to the Ga-In bath and through radiation from the surface.

In the case of natural convection, for low values of Prandtl number, the Nusselt number for heat transfer is given by (McAdams 1954):

$$
\mathrm{Nu}=0.68\left(\frac{\mathrm{Pr}}{0.952+\operatorname{Pr}}\right)^{1 / 4}(\mathrm{Gr} \mathrm{Pr})^{1 / 4}
$$

where, $\mathrm{Gr}$ is the Grashof number given by:

$$
\mathrm{Gr}=g \beta\left(T_{S}-T_{A}\right) L^{3} / v^{2},
$$

where, $g$ is the acceleration due to gravity and $\beta$ is the coefficient of thermal expansion. 
(a)

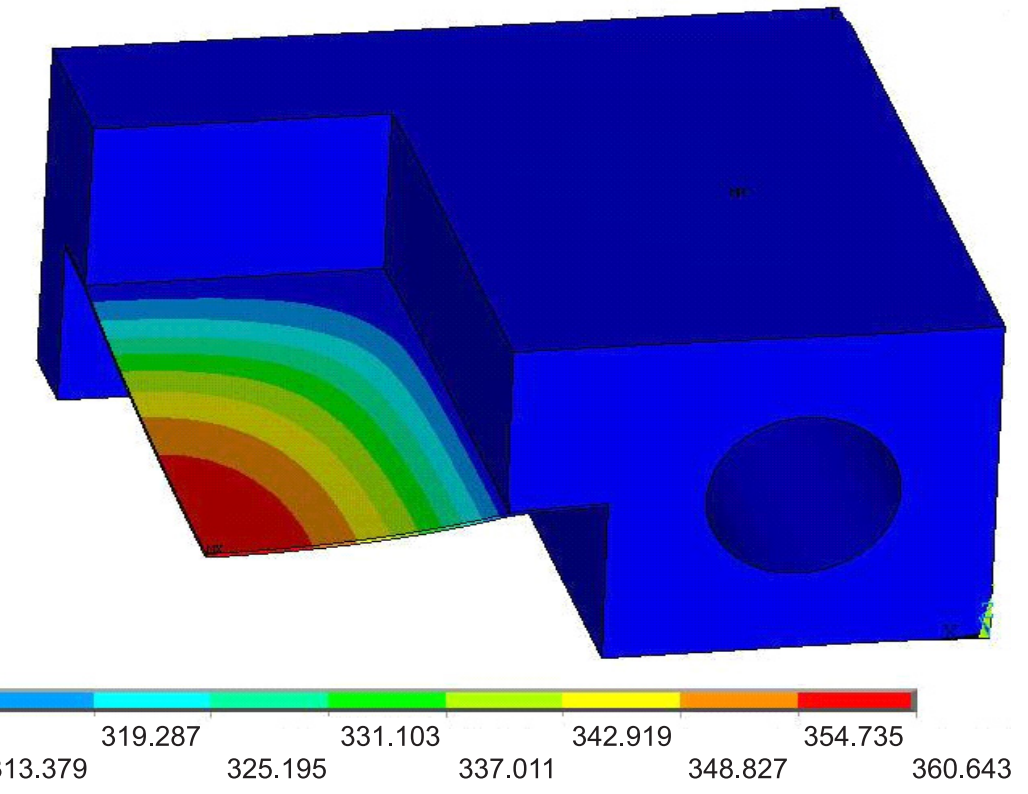

(b)
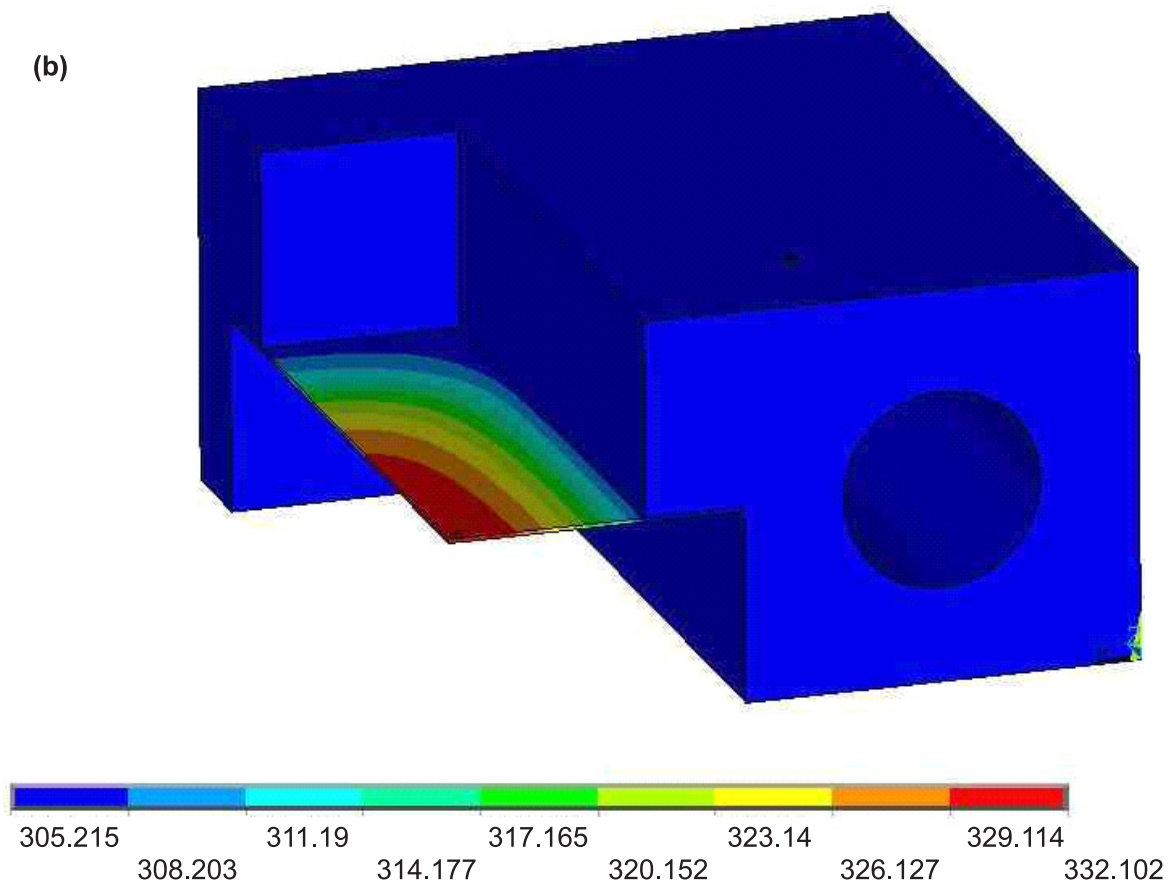

Figure 16. Temperature distribution on the Be window for heat transfer coefficient of $2500 \mathrm{Wm}^{2} \mathrm{~K}^{-1}$. (a) type-I window, and (b) type-II window (temperatures in kelvin). 


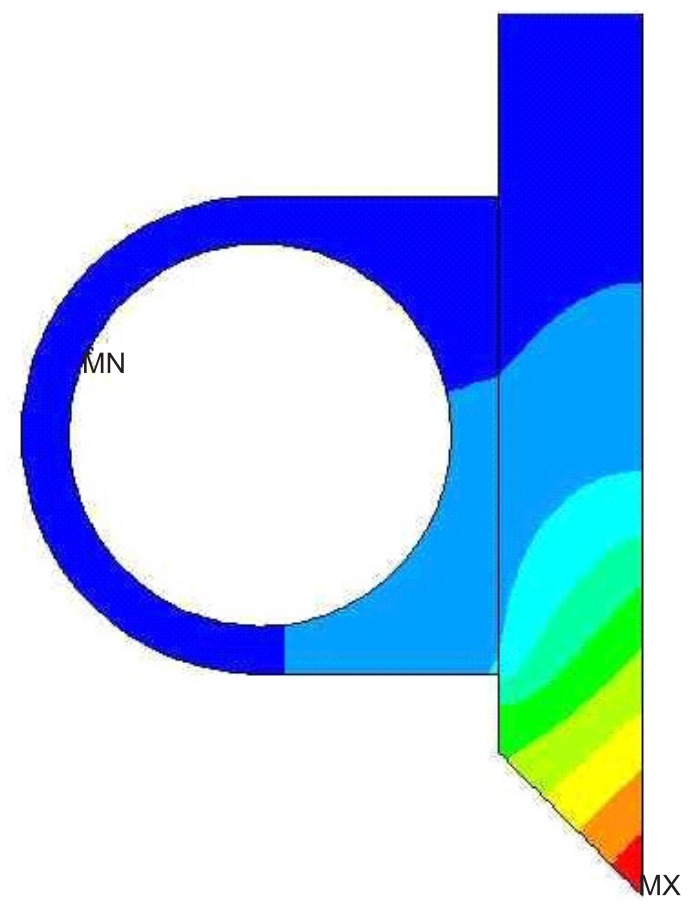

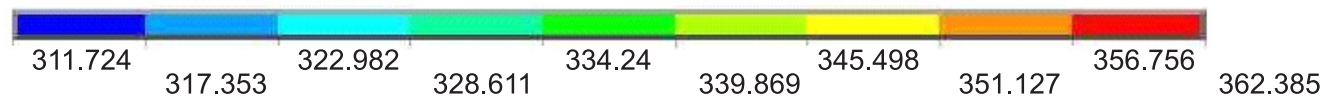

Figure 17. Temperature distribution on one of the vertical tantalum jaws of the slit system for $2.0 \mathrm{~m} \mathrm{~s}^{-1}$ flow rate of water through the cooling channels as shown in the figure (temperatures are in kelvin).

The schematic diagram of the crystal is shown in figure 7 with the relevant dimensions. The different thermo-physical parameters of the $\mathrm{Ga}-\mathrm{In}$ bath required for this calculation have been shown in table 5 (Koster 1999). The heat transfer coefficient is calculated to be $3270 \mathrm{Wm}^{-2} \mathrm{k}^{-1}$ and the liquid temperature has been assumed to be $300 \mathrm{~K}$. Assuming the above values, the temperature distribution in the crystal under bent condition has been calculated and the result is shown in figure 18a. The maximum temperature at the central portion of the crystal can be

Table 5. Thermo-physical properties of Ga-In mixture.

\begin{tabular}{lc}
\hline Property & Value \\
\hline Density @ 302 K & $6.2275 \mathrm{~g} \mathrm{~cm}^{-3}$ \\
Thermal expansion coefficient & $1.065 \times 10^{-4} \mathrm{~K}^{-1}$ \\
Kinematic viscosity & $3.213 \times 10^{-7} \mathrm{~m}^{2} \mathrm{~s}^{-1}$ \\
Thermal diffusivity & $1.379 \times 10^{-5} \mathrm{~m}^{2} \mathrm{~s}^{-1}$ \\
Thermal conductivity in liquid & $25.5 \mathrm{Wm}^{-1} \mathrm{~K}^{-1}$ \\
\hline
\end{tabular}




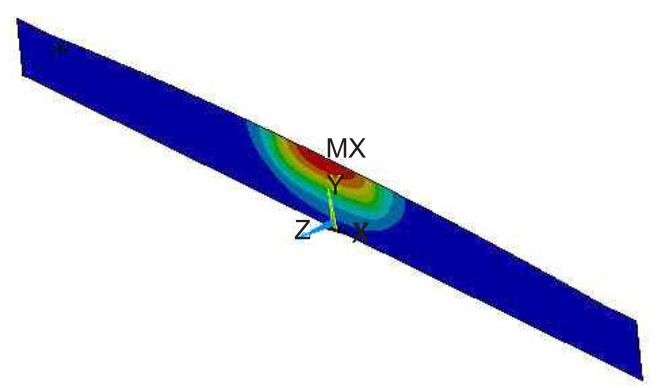

(a)
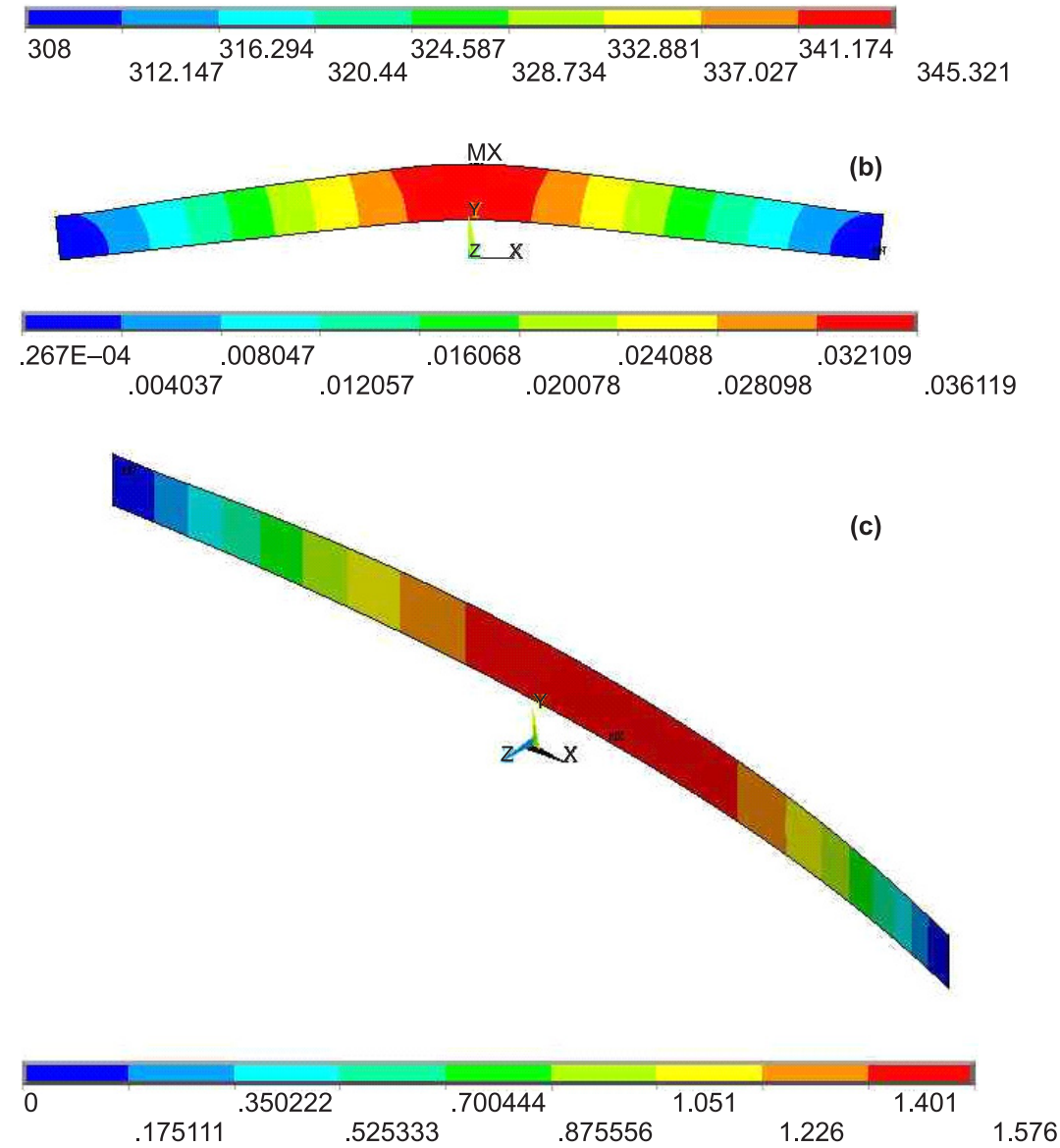

Figure 18. Distribution of (a) temperature, (b) thermal deflection due to the heat load in the Si crystal, and (c) total deflection due to mechanical bending and heat load in the Si crystal with cooling through a Ga-In bath (temperatures in kelvin and deflections in $\mathrm{mm}$ ). 
brought down to $72^{\circ} \mathrm{C}$ with this cooling configuration. The thermal deflection generated in the crystal under this configuration has been simulated using the mechanical properties of the crystal as reported in the literature (Ygural \& Senster 1995) and has been shown in figure 18b. Figure $18 \mathrm{c}$ shows the deflection (in $\mathrm{mm}$ ) generated in the crystal under the bent condition due to the combined effect of mechanical bending and thermal load, and it has been observed that the thermal deflection present in the crystal with the cooling arrangement is negligible compared to the mechanical deflection present in the crystal in the bent condition.

\section{Summary}

An extended X-ray absorption fine structure (EXAFS) beamline is being developed for the INDUS-II synchrotron source. The results of temperature distribution simulation by finite element analysis on different optical and mechanical components of the EXAFS beamline on exposure to the synchrotron beam have been presented here. It is found that there is significant temperature rise in the range of $450-600^{\circ} \mathrm{C}$ at different components of the beamline under exposure to synchrotron radiation. The design of the cooling mechanism for each of these components has also been carried out and it has been observed by finite element simulation that with an optimized cooling arrangement, the temperature rise in the above components can be restricted to reasonable values.

The authors wish to acknowledge the contribution of V K Mishra and A K Sinha of the Centre for Design and Manufacture in the mechanical design of the crystal bender. One of us (NCD) acknowledges the financial support from the Department of Atomic Energy - Board of Research in Nuclear Sciences.

\section{References}

Ascone I, Meywr-Klaucke W, Murphy L 2003 Experimental aspects of biological X-ray absorption spectroscopy. J. Synchron. Rad. 10: 16-22

Das N C, Jha S N, Roy A P 1999 Optical design of an X-ray absorption spectroscopy beamline at INDUS-2 synchrotron radiation source. Report No. E/035, Bhabha Atomic Research Centre, Mumbai

Das N C, Jha S N, Bhattacharyya D, Sinha A K, Mishra V K, Verma V, Ghosh A K 2002 Optical and mechanical design of the extended X-ray absorption fine structure (EXAFS) beamline at INDUS-II synchrotron source. Report No. E/030, Bhabha Atomic Research Centre, Mumbai

Das N C, Jha S N, Bhattacharyya D 2004 Design of the extended X-ray absorption fine structure (EXAFS) beamline at INDUS-II synchrotron source. Eighth Int. Conf. on Synchrotron Radiation Instrumentation (SRI-2003) (New York: American Institute of Physics) 705: 301-304

Das N C, Jha S N, Bhattacharyya D 2004 Design, fabrication and testing of elliptical crystal bender for the EXAFS beamline at INDUS-II synchrotron source. Sādhanā 29: 545-557

Eckert E R G 1950 Introduction to the transfer of heat and mass transfer (New York: McGraw Hill)

Henke B L, Gullikson E M, Davis J C 1993 X-ray interactions: Photoabsorption, scattering, transmission, and reflection at $E=50-30,000 \mathrm{eV}, Z=1-92$. Atomic Data Nuclear Data Tables 54: $181-342$

Hricovini K et al 2003 Atomic structure and magnetic properties of Mn on InAs(1 0 0). App. Surf. Sci. 212-213: 17-25 
Iwasawa Y 2003 In situ characterization of supported metal catalysts and model surfaces by timeresolved and three-dimensional XAFS techniques. J. Catal. 216: 165-177

Koch E E, Eastman D E, Farges Y 1983 Synchrotron radiation - A powerful tool in science. In handbook on synchrotron radiation (ed.) E E Koch (Amsterdam: North-Holland) vol. 1

Koster J N 1999 Directional solidification and melting of eutectic GaIn. Cryst. Res. Technol. 34: $1129-1140$

Lee P L, Beno M A, Jennings G, Ramanathan M, Knapp G S, Huang K, Bai J, Montano P A 1994 An energy dispersive x-ray absorption spectroscopy beamline, X6A, at NSLS. Rev. Sci. Instrum. 65: $1-6$

Lide D R (ed.) 1999 CRC handbook of chemistry \& physics (Boca Raton, Fl: CRC Press)

Lytle F W 1999 The EXAFS family tree: A personal history of the development of extended X-ray absorption fine structure. J. Synchron Rad. 6: 123-134

Mc Adams W 1954 Heat transmission (New York: McGraw-Hill)

Stern E A 2001 Musings about the development of XAFS. J. Synchron Rad. 8: 49-54

Tournus F, Masenelli B, Melinon P, Blasé X, Perez A, Pellkarin M, Broyer M, Flank A M, Lagarde P 2002 Bridging $\mathrm{C}_{60}$ by silicon: Towards non-Van der Waals $\mathrm{C}_{60}$-based materials. Phys. Rev. B65: 165417-165422

Ygural A C, Senster S K 1995 Advanced strength \& applied elasticity (Englewood Cliffs, NJ: PrenticeHall) 